\title{
Natural composites based on polysaccharide derivatives: preparation and physicochemical properties
}

\author{
Adrian K. Antosik ${ }^{1} \cdot$ Katarzyna Wilpiszewska ${ }^{2}$ \\ Received: 7 June 2018 / Accepted: 3 July 2018 / Published online: 7 July 2018 \\ (c) The Author(s) 2018
}

\begin{abstract}
Preparation of the novel biodegradable composite based on carboxymethyl derivatives of starch and cellulose as well as microcrystalline cellulose was described. The effect of filler content (1-7 phr) on the physicochemical properties (moisture sorption, water solubility, mechanical properties) of the resulting films was determined. With the filler amount increase the Young's modulus increased from 4.8 up to $32.4 \mathrm{MPa}$, while the solubility in water dropped from 64 to $58 \%$, for the system without, and containing $7 \mathrm{phr}$ microcrystalline cellulose, respectively.
\end{abstract}

Keywords Carboxymethyl starch $\cdot$ Carboxymethyl cellulose $\cdot$ Microcrystalline cellulose $\cdot$ Natural composite Biodegradable film

Plastic films are widely used in the packaging, agriculture and medicine industries. Biodegradable films based on polysaccharides may be an alternative to commonly used plastic films obtained from petrochemical sources. Starch being renewable, relatively cheap and easily modifiable natural polymer seems to be a promising raw material for the biodegradable films production. They meet the principle of " $5 \mathrm{E}$ ", which are efficiency, energy saving, enabling, economy and environmental friendly (Almasi et al. 2010; Avella et al. 2005; Ghanbarzadeh and Almasi 2011; Koo et al. 2010).

The etherification of starch to the carboxymethyl derivative allows obtaining the polymer soluble in cold water. The physicochemical properties of carboxymethyl starch (CMS), such as the dissolution rate and viscosity of aqueous solutions, mainly determine the degree of substitution (DS, average number of substituted hydroxyl groups in the unit of repetitive starch) and molecular weight. The values of these parameters depend mainly on the type of starch as

Adrian K. Antosik

adriankrzysztofantosik@gmail.com

1 Institute of Organic Chemical Technology, West Pomeranian University of Technology Szczecin, ul. Pulaskiego 10, 70-322 Szczecin, Poland

2 Polymer Institute, West Pomeranian University of Technology Szczecin, ul. Pulaskiego 10, 70-322 Szczecin, Poland well as the method of its modification (Spychaj et al. 2013a; Mazikova et al. 2009).

Carboxymethyl derivative of cellulose (CMC) was often used for film preparation (Almasi et al. 2010; Ghanbarzadeh and Almasi 2011; Spychaj et al. 2013a; Bystricky et al. 1998). However, there are only few reports on preparing CMS-based films. CMS is a carboxymethyl derivative less expensive than CMC, which is the result of higher price of the cellulosic raw material as well as the necessity of using harmful organic solvents for cellulose modification. Therefore, applying CMS seems to be beneficial in terms of the environmental issues (Wilpiszewska et al. 2015).

Microcrystalline cellulose (MCC) was used as a filler in PE matrix (Miyazaki et al. 2012). Its addition had positive effect on the mechanical properties of the composite (higher modulus of elasticity) maintaining good product transparency. In the packaging industry, MCC was used as an additive to starch-based film (Avella et al. 2005). The similar effect of starch-based film with high content of MCC as in PE matrix was observed-increased the tensile strength (Psomiadou et al. 1996).

In this paper, natural composite was obtained applying polysaccharide carboxymethyl derivatives of starch and cellulose (with citric acid as crosslinking agent) reinforced with microcrystalline cellulose filler. The effect of MCC content (1-7 phr) on the physicochemical properties of the resulting material has been determining. 
The method of CMS preparation was reported by Spychaj et al. (2013b). For that purpose potato starch (Nowamyl S.A., Poland), sodium hydroxide (POCH, Poland), chloroacetic acid (tech.) and 2-propanol (tech.) (Chempur, Poland) was used. For composite preparation, carboxymethyl cellulose (DS: 0.7, Pollocel AS-2/90) from Pronicel Sp. o.o. (Poland), monohydrate citric acid (CA) (p.a.), plasticizer-glycerol (p.a.) (both Chempur, Poland) and microcrystalline cellulose (tech.) from Aldrich were applied.

The synthesis of carboxymethyl starch was carried out using the one-step method. In the glass reactor, monochloroacetic acid and isopropanol were placed (the medium was saturated with nitrogen, after which the acid was neutralized with an aqueous solution of sodium hydroxide in a molar ratio of 1:1). When the color of reactor content turned milky white, the system was stirred for $10 \mathrm{~min}$ (200 rpm), and subsequently starch and hydroxide were added. The mixture was stirred for $2.5 \mathrm{~h}$ at $50{ }^{\circ} \mathrm{C}$. Then the solution was neutralized to $\mathrm{pH}$ 6. The product was filtered under reduced pressure and washed five times with an $80 \%$ methanol solution, and the last one with undiluted methanol. The carboxymethyl starch with a degree of substitution of 0.70 (Spychaj et al. 2013b) was obtained.

An aqueous dispersion of microcrystalline cellulose was prepared in a beaker by measuring $100 \mathrm{~g}$ water and 1, 3, 5 or $7 \mathrm{phr}$ of MCC on a basis of polysaccharide derivatives mass; the system was stirred for $30 \mathrm{~min}$. Then a mixture of CMS and CMC (1:1 by weight) was added to the system and stirred for $30 \mathrm{~min}$. Subsequently, $2 \mathrm{~g}$ glycerol and $2 \mathrm{~g}$ citric acid were added and mixed until homogeneity. Then the system was poured into PTFE molds and placed in a dryer for $48 \mathrm{~h}$ at $60{ }^{\circ} \mathrm{C}$. The obtained films (thickness $200-300 \mu \mathrm{m}$ ) were removed from the mold and tested.

Three samples $(1.5 \mathrm{~cm} \times 1.5 \mathrm{~cm})$ were cut from the film and placed in a desiccator to remove moisture (to constant mass). The samples were then weighed, placed in vials and filled with $50 \mathrm{ml}$ distilled water. After $24 \mathrm{~h}$ the samples were removed, and dried for about $24 \mathrm{~h}\left(60{ }^{\circ} \mathrm{C}\right)$ to constant mass. The dry samples were again weighed. The solubility in water values was calculated using the following formula (Almasi et al. 2010; Wilpiszewska et al. 2015):

$\mathrm{TSM}=\left[\left(M_{1}-M_{2}\right) / M_{1}\right] \times 100 \%$,

where TSM (total soluble mater) the solubility in water (\%); $M_{1}$ the mass of the dry sample (g); $M_{2}$ the mass of the sample after drying $(\mathrm{g})$.

Three samples $(1.5 \mathrm{~cm} \times 1.5 \mathrm{~cm})$ were cut from the film and placed in a desiccator to remove moisture (to constant mass). The samples were then weighed, and placed in a climate chamber (humidity $55 \pm 2 \%$, temperature $25 \pm 2{ }^{\circ} \mathrm{C}$ ). The samples were weighed 3, 5, 7, 24, 48 and $72 \mathrm{~h}$ after being placed in the climatic chamber. The results obtained in this way were substituted for the formula (Almasi et al. 2010):

$A_{t}=\left[\left(M_{t}-M_{0}\right) / M_{0}\right] \times 100 \%$,

where $A_{t}$ the sorption of moisture after time $t(\%) ; M_{0}$ the mass of the dry sample $(\mathrm{g}) ; M_{t}$ the sample mass after $t$ time: $3,5,7,24,48$ and $72 \mathrm{~h}(\mathrm{~g})$.

Tensile strength of the films was tested using the INSTRON testing machine. The initial length of the sample was $50 \mathrm{~mm}, 10 \mathrm{~mm}$ wide, and about $0.2 \mathrm{~mm}$ thick. The speed of the mobile clamp was $10 \mathrm{~mm} / \mathrm{min}$. Seven samples of one material type were tested (Roy et al. 2012).

Thermal analysis was carried out using the DMTA Q800 (TA Instruments) apparatus in the temperature range -30 to $180{ }^{\circ} \mathrm{C}$ with a heating rate of $3{ }^{\circ} \mathrm{C} / \mathrm{min}$ and an amplitude of $15 \mathrm{~nm}$.

In Fig. 1, the effect of microcrystalline cellulose into the CMS/CMC system has been presented. Introducing MCC into polysaccharide derivative-based matrix resulted in slight moisture sorption increase when compared to the unfilled system (24 and 20\% for the system containing 3 and $0 \mathrm{phr}$ MCC, respectively), suggesting more loosen structure of composite when compared to the neat system. However, for higher MCC content, a slight decrease of this parameter was noted. The explanation could be the intermolecular interaction between polysaccharide derivatives and MCC macromolecules resulting in more dense structure.

In Fig. 2, the effect of MCC addition on solubility in water of CMS/CMC based composite has been presented. Even low microcrystalline cellulose content ( $1 \mathrm{phr}$ ) resulted in reduced solubility in water. The reason could be the possibility of hydrogen bonds formation between carboxyl groups of polysaccharide carboxymethyl derivatives and citric acid. Additionally, they could also may interact with cellulosic filler resulting in a more dense structure, and as a result, in reduced solubility in the water of the composite material, what correlate to the moisture sorption results.

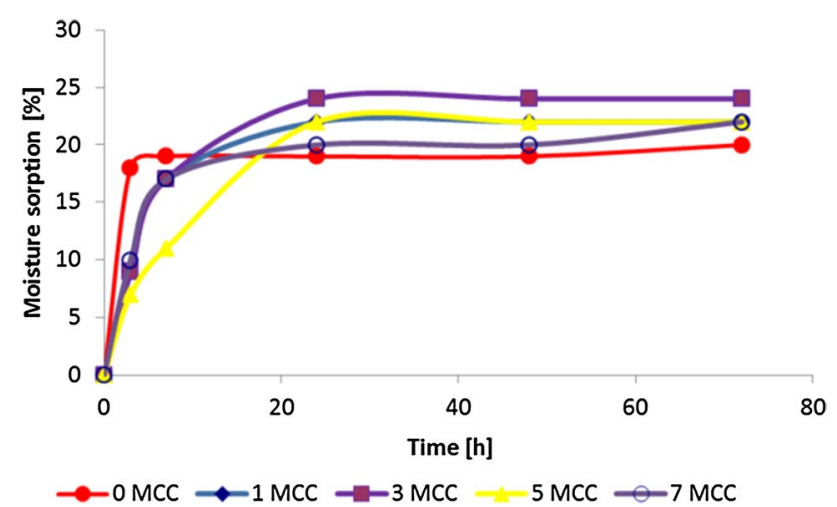

Fig. 1 Influence of MCC content on moisture sorption of CMS/ CMC-based films 


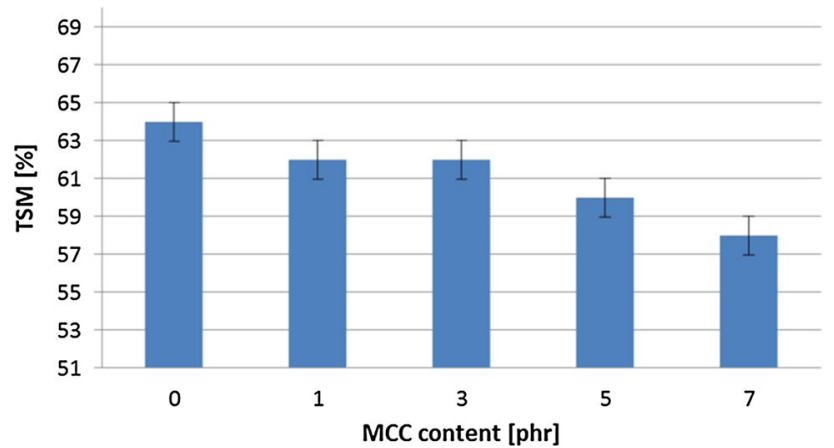

Fig. 2 Influence of MCC content on solubility in water of CMS/ CMC-based films

In Table 1, the mechanical parameters of the polysaccharide derivatives system containing various amount of MCC have been collected. With the higher filler content increase, both Young's modulus and tensile strength increase was noted (the highest values of these parameters were noted for a system containing $7 \mathrm{phr}$ MCC, 32.4 and $1.8 \mathrm{MPa}$, respectively). The observed tensile strength increase for the films with the higher microcrystalline cellulose content is probably caused by the formation of hydrogen bonds between polysaccharide derivatives and the cellulose filler. However, for the lower amounts of MCC added the values of both parameters were similar the neat system ones. Moreover, the elongation at break for these systems was higher than for unfilled film, suggesting inefficient interactions between macromolecules and the structure of lower density.

Figure 3 shows DMTA curves of CMS/CMC films with various microcrystalline cellulose contents. However, no significant effect on the thermal properties of the natural composite has been observed.

The natural composites based on CMS and CMC derivatives containing microcrystalline cellulose as filler have been prepared. Introducing MCC beneficially affected the mechanical parameters of the CMS/CMC films, as Young's modulus and tensile strength increase was observed (for the

Table 1 Influence of MCC content on elongation at break, Young's modulus and tensile strength of CMS/CMC-based films

\begin{tabular}{llll}
\hline $\begin{array}{l}\text { MCC content } \\
(\mathrm{phr})\end{array}$ & $\begin{array}{l}\text { Elongation at } \\
\text { break (\%) }\end{array}$ & $\begin{array}{l}\text { Young's modulus } \\
(\mathrm{MPa})\end{array}$ & $\begin{array}{l}\text { Tensile } \\
\text { strength } \\
(\mathrm{MPa})\end{array}$ \\
\hline 0 & $29 \pm 0.5$ & $4.8 \pm 0.1$ & $1.2 \pm 0.1$ \\
1 & $39 \pm 0.5$ & $3.4 \pm 0.1$ & $1.3 \pm 0.1$ \\
3 & $53 \pm 0.5$ & $5.3 \pm 0.1$ & $1.4 \pm 0.1$ \\
5 & $27 \pm 0.5$ & $13.4 \pm 0.1$ & $1.6 \pm 0.1$ \\
7 & $28 \pm 0.5$ & $32.4 \pm 0.1$ & $1.8 \pm 0.1$ \\
\hline
\end{tabular}

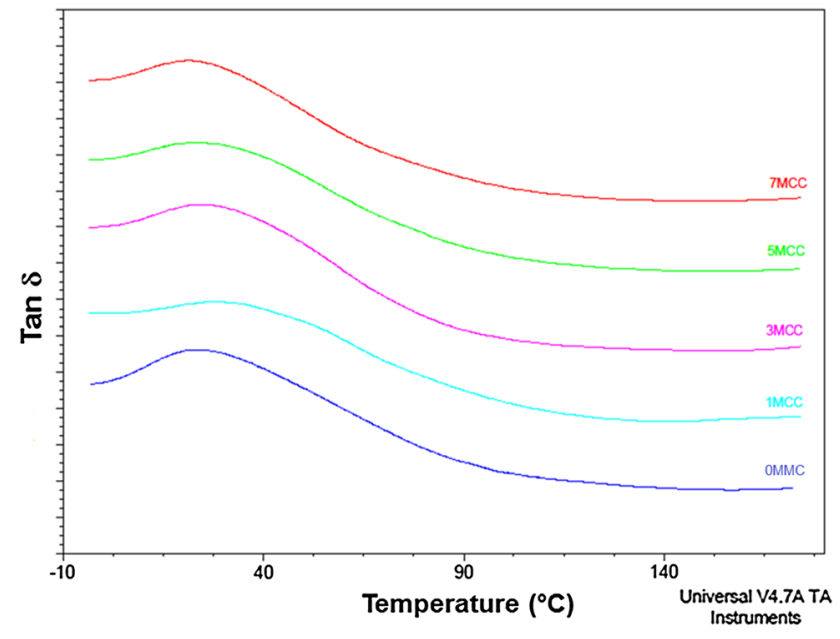

Fig. 3 DMTA curves of CMS/CMC-based films with various MCC contents

system without and with $7 \mathrm{phr}$ MCC from 4.8 to $32.4 \mathrm{MPa}$ and from 1.3 to $1.8 \mathrm{MPa}$, respectively). Moreover, the solubility in water was reduced. These were probably caused by the formation of hydrogen bonds between polysaccharide derivatives and the cellulose filler resulting in more dense structure of the composite. However, the presence of cellulosic filler did not affect the thermal properties of the natural composite.

Open Access This article is distributed under the terms of the Creative Commons Attribution 4.0 International License (http://creativecommons.org/licenses/by/4.0/), which permits unrestricted use, distribution, and reproduction in any medium, provided you give appropriate credit to the original author(s) and the source, provide a link to the Creative Commons license, and indicate if changes were made.

\section{References}

Almasi H, Ghanbarzadeh B, Entezami AA (2010) Physicochemical properties of starch-CMC-nanoclay biodegradable films. Int J Biol Macromol 46:1-5. https://doi.org/10.1016/j.ijbio mac.2009.10.001

Avella M, De Vlieger JJ, Errico ME, Fischer S, Vacca P, Volpe MG (2005) Biodegradable starch/clay nanocomposite films for food packaging applications. Food Chem 93:467-474. https://doi. org/10.1016/j.foodchem.2004.10.024

Bystricky S, Machova E, Kogan G (1998) Preparation and characterization of a biological carrier based on carboxymethyl cellulose. Chem Pap 52:374

Ghanbarzadeh B, Almasi H (2011) Physical properties of edible emulsified films based on carboxymethyl cellulose and oleic acid. Int J Biol Macromol 48:44-49. https://doi.org/10.1016/j.ijbio mac.2010.09.014

Koo SH, Lee KY, Lee HG (2010) Effect of cross-linking on the physicochemical and physiological properties of corn starch. Food Hydrocoll 24:619-625. https://doi.org/10.1016/j.foodhyd.2010.02.009 
Mazikova V, Srokova I, Ebringerova A (2009) Solvent-free synthesis and properties of carboxymethyl starch fatty acid ester derivatives. Chem Pap 63:71-76. https://doi.org/10.2478/s11696-008-0088-x

Miyazaki K, Hamadate M, Terano M, Nakatani H (2012) Syndiotactic polypropylene/microfibrous cellulose composites: effect of filler size on tensile properties. J App Polym Sci 128:1-8. https://doi. org/10.1002/app.38284

Psomiadou E, Arvanitoyannis I, Yamamoto N (1996) Edible films made from natural resources; microcrystalline cellulose (MCC) and corn starch and polyols-part 2. Carbohyd Polym 31:193204. https://doi.org/10.1016/S0144-8617(96)00077-X

Roy N, Saha N, Kitano T, Saha P (2012) Biodegradation of PVP-CMC hydrogel film: a useful food packaging material. Carbohydr Polym 89:346-353. https://doi.org/10.1016/j.carbpol.2012.03.008
Spychaj T, Wilpiszewska K, Zdanowicz M (2013a) Medium and high substituted carboxymethyl starch: synthesis, characterization and application. Starch 65:22-33. https://doi.org/10.1002/star.20120 0159

Spychaj T, Zdanowicz M, Kujawa J, Schmidt B (2013b) Carboxymethyl starch with high degree of substitution: synthesis, properties and application. Polimery 58:501-509

Wilpiszewska K, Antosik AK, Spychaj T (2015) Novel hydrophilic carboxymethyl starch/montmorillonite nanocomposite films. Carbohydr Polym 128:82-89. https://doi.org/10.1016/j.carbp ol.2015.04.023 